\title{
Evaluating the Effect of Light Intensity on Flower Development Uniformity in Strawberry (Fragaria $\times$ ananassa) under Early Induction Conditions in Forcing Culture
}

\author{
Rui Wang and Masatake Eguchi \\ Institute of Vegetable and Floriculture Science, National Agriculture and \\ Food Research Organization, Tsukuba, Ibaraki 305-8517, Japan
}

Yuqing Gui

Assessment Center of Jiangsu Provincial Department of Agriculture and Rural Affairs, China

Yasunaga Iwasaki

Institute of Vegetable and Floriculture Science, National Agriculture and Food Research Organization, Tsukuba, Ibaraki 305-8517, Japan

Additional index words. flowering, inflorescence, photoperiod, LED, shade, environment

Abstract. Uniform flower development is crucial for the uniform production of mature fruit, and it is essential in the management and production of commercial strawberry (Fragaria $\times$ ananassa) in greenhouses. Environmental factors such as temperature, light intensity, and photoperiod have been extensively evaluated to determine their roles in strawberry flower induction and growth; however, data on the role that lighting conditions play in the uniformity of flower development are still lacking. The aim of this study was to clarify the influence of light intensity on the uniformity of strawberry flower development in forcing culture. Two experiments were conducted to evaluate plants' response to both shading and light-emitting diode (LED) treatments. Plant growth parameters (i.e., leaf area, dry matter, and number of leaves between inflorescences) and flower development data [i.e., time from flower beginning to full bloom (FB), time from transplanting to flowering (TB), and bud number (BN)] were recorded. As expected, flower development was enhanced when exposed to LED light and was delayed when shaded. Within each cultivar, a strong relationship between lighting environment and uniformity of flower development was also detected. In both experiments, TB and BN showed less variation when exposed to high light intensity compared with low intensity. This trend was true for other parameters as well, including dry matter, leaf area, and number of leaves between inflorescences. However, there were no significant differences in FB between the shading and LED treatments. The results show that strawberry growth and flower development were highly variable in a low light environment. In addition to light being an important factor in inflorescence initiation and high yield production, the results of this study also show that the amount of light supplied is an important factor in maintaining uniform flowering in forcing culture.

Flowering in strawberry is known to be significantly affected by temperature and photoperiod (Kumakura and Siilsiildo, 1995), and the floral initiation of strawberry is regulated by a complex set of environmental and physiological cues (Awang and Atherton, 1995; Opstad et al., 2011; Sønsteby et al., 2013). Furthermore, the appearance and development of inflorescences are

Received for publication 6 Feb. 2020. Accepted for publication 4 Mar. 2020.

Published online 9 April 2020.

Y.I. is the corresponding author. E-mail: iwasakiy@ affrc.go.jp.

This is an open access article distributed under the CC BY-NC-ND license (https://creativecommons. org/licenses/by-nc-nd/4.0/). significantly influenced by genotype as well as several environmental factors such as temperature, light intensity, and light quality/photoperiod (Nestby and Sønsteby, 2017; Zahedi and Sarikhani, 2017). Researchers have attempted to explain how various lighting environments affect plant physiological responses such as leaf initiation, time to flowering, flowering rate, and fruit quality. Cervantes et al. (2019) evaluated several strawberry genotypes under multiple light exposure treatments and evaluated how genotype and light exposure interactions affected fruit quality. Choi et al. (2016) showed correlations between multiple photosynthesis-related parameters and lighting environment by measuring fruit productivity. Tsuruyama and Shibuya (2018) reported that different photoperiods in controlled environment chambers altered the growth and flowering responses in seedpropagated strawberry seedlings; moreover, flower bud initiation after transplanting was likely accelerated by increasing the photoperiod length. Takeda et al. (2010) evaluated the effect of using photoselective shade nets over strawberry plug plants and concluded that because of the removal of the light signal that initiates flowering, the initiation of flower buds was delayed. Overall, research has shown that increasing both light and photoperiod increases productivity and fruit quality. However, most studies focus on individual strawberry plants of different genotypes and their response to different lighting conditions or different light effects on growth and yield (Cervantes et al., 2019; Choi et al., 2014; Mochizuki et al., 2019; Nestby and Sønsteby, 2017; Young and Ho, 2013). Understandably, the number of buds determines the harvest to a large degree. Therefore, evaluating the variability of flowering characteristics of a whole population will likely produce results that are more applicable in a commercial production setting as compared with genotypic response evaluations.

In Japan, strawberry plants are transplanted once the differentiation of primary inflorescence has occurred into commercial off-season production greenhouses in midSeptember, and the fruit is harvested from late November to June (Kumakura and Siilsiildo, 1995; Yoshida et al., 1997, 2012). Owing to environmental conditions and seasonal changes that occur after transplanting, the time to flowering of the second inflorescence increases, which is directly related to the increase in time required for fruit formation. Uniform flower development is also directly related to how uniformly fruits mature, which is important for the logistics and planning in commercial production. Furthermore, to improve harvesting techniques and increase fruit shelf life, Miyashita et al. (2019) suggested that investigating and promoting flowering uniformity would promote uniformity of maturation and allow cluster harvesting in blueberries.

To analyze the effects of different lighting conditions, we applied shading treatments and light-emitting diode (LED) exposure treatments. The aims of this study were 1) to investigate the variability of uniform flower development in different light environments and 2) to evaluate the photosynthetic performance of strawberry and how it is related to maintaining uniformity with a population.

\section{Materials and Methods}

Experimental design and growing conditions. Two experiments were performed, the first one in 2015 and the second one in 2018. Two strawberry cultivars, Mouikko and Tochiotome, were used in the first experiment. 'Mouikko' has been a standard cultivar for farmers in Miyagi Prefecture for many years, and 'Tochiotome' is currently the most 

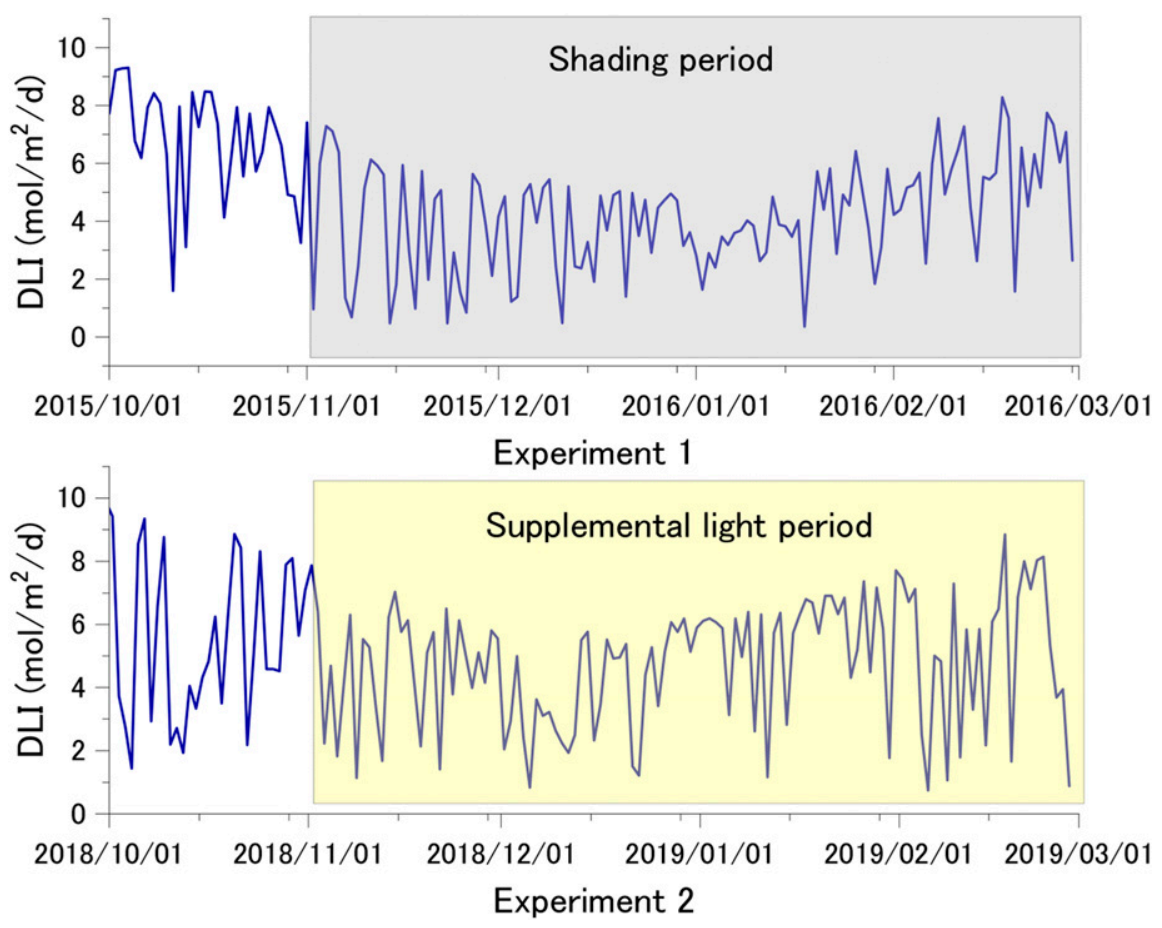

Fig. 1. Variations of daily light integral (DLI) during Expts. 1 and 2.
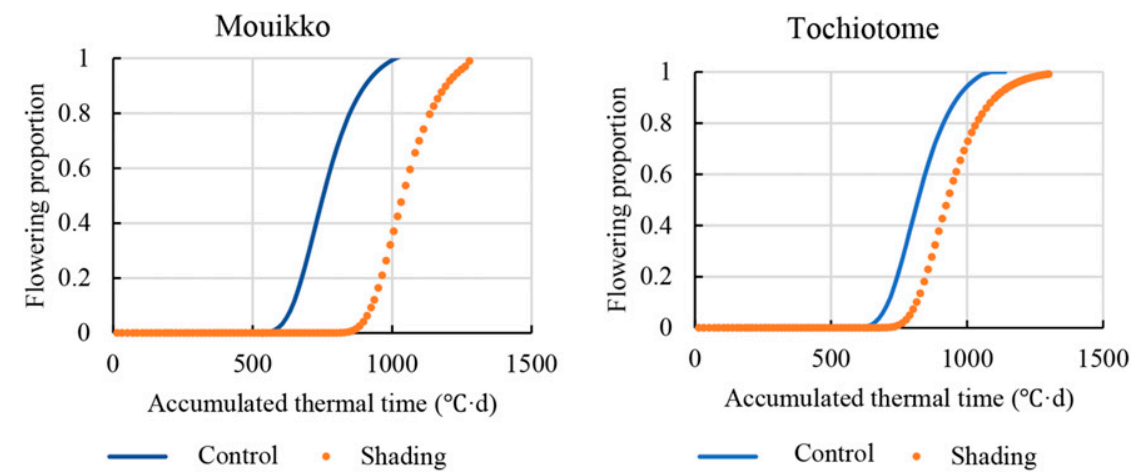

Fig. 2. Proportion of strawberry plants reaching flowering as a function of thermal time (sum of daily mean temperature after transplanting) under shading treatments of the first experiment $(n=10)$.
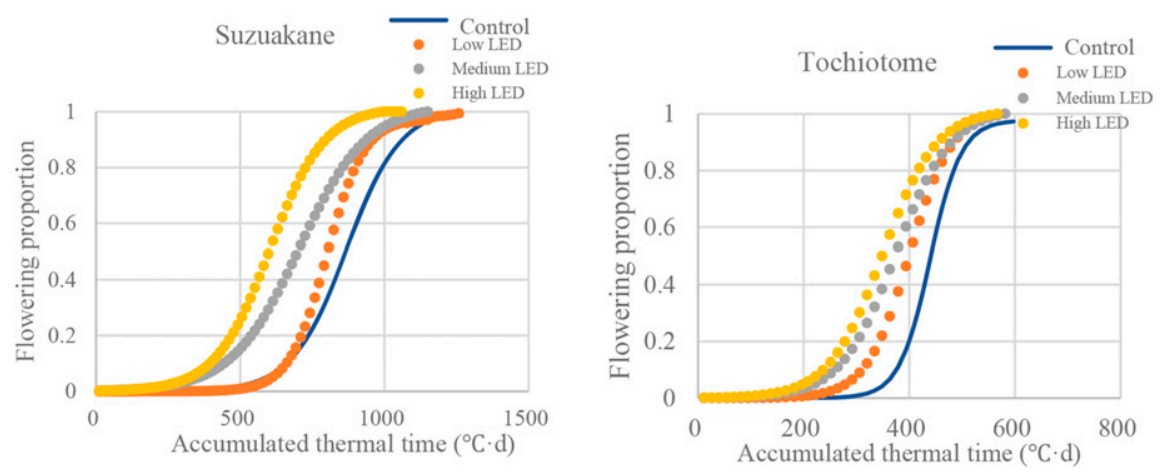

Fig. 3. Proportion of strawberry plants reaching flowering as a function of thermal time (sum of daily mean temperature after transplanting) under four lighting exposure treatments of the second experiment $(\mathrm{n}=7)$.

popular cultivar in Japan, owing to its high production volume. In the second experiment, cultivars of Suzuakane and Tochiotome were used. 'Suzuakane' is an everbearing type. The other two cultivars, under natural light conditions. The plants were grown under greenhouse conditions at GRA Co. Ltd., Miyagi, Japan. Once rooted, the daughter plants were potted into plug trays using a peat-based potting compost and grown under the same greenhouse conditions as before transplanting. The plugs were transplanted in mid-Sept. 2015 into polyethylene pots $(13.5 \mathrm{~cm}$ diameter $\times 11 \mathrm{~cm}$ depth; $1.2 \mathrm{~L}$ volume), with a river sand soil substrate at a density of 4.4 plants $/ \mathrm{m}^{2}(15 \mathrm{~cm}$ apart in rows $25 \mathrm{~cm}$ apart). They were fertigated with OAT-A Nutrient Solution (OAT Agrio Co., Ltd., Tokyo, Japan). The fertigation solution consisted of $8.8 \mathrm{mM} \mathrm{NO}_{3}, 5.1 \mathrm{mM} \mathrm{K}^{+}, 4.1 \mathrm{~mm}$ $\mathrm{Ca}^{2+}, 1.5 \mathrm{~mm} \mathrm{Mg}{ }^{2+}, 0.7 \mathrm{~mm} \mathrm{H} \mathrm{PO}_{4}, 3 \mathrm{mg} \cdot \mathrm{L}^{-1}$ iron, $0.05 \mathrm{mg} \cdot \mathrm{L}^{-1}$ manganese, $0.5 \mathrm{mg} \cdot \mathrm{L}^{-1}$ boron, $0.05 \mathrm{mg} \cdot \mathrm{L}^{-1}$ zinc, $0.02 \mathrm{mg} \cdot \mathrm{L}^{-1}$ copper, and $0.01 \mathrm{mg} \cdot \mathrm{L}^{-1}$ molybdenum, which was adjusted to an electric conductivity of 0.7 and a $\mathrm{pH}$ of 6.0. The supply of nutrient solution was applied daily at three points throughout the day ( $50 \mathrm{~mL}$ at a time) with a drip irrigation system. The temperature inside the greenhouse was controlled by heating and ventilation to maintain an $\approx 25{ }^{\circ} \mathrm{C} /$ $10^{\circ} \mathrm{C}$ (day/night) environment. At the end of November, plastic film curtains were drawn, and a heater began to work to maintain night air temperatures above $10{ }^{\circ} \mathrm{C}$. The shading treatment was applied 7 weeks after transplanting using polyethylene film (Dio karucool SW-50, Diochemicals, Ltd., Japan) suspended $1.0 \mathrm{~m}$ above the cultivation bed. During the day, light intensity at the canopy level under the shaded netting was maintained at $50 \%$ of the light intensity of the unshaded area.

The second experiment took place between late Nov. 2018 and the end of Feb. 2019. Plants were grown under greenhouse conditions at the National Agriculture and Food Research Organization, Institute of Vegetable and Floriculture Science (Kannondai, Tsukuba, Ibaraki, Japan). Plants were transplanted at the same density and fertilized with the same solution as in the first experiment. To evaluate the effects of supplemental LED lighting, three photo intensities [referred to as high LED $\left(80 \mu \mathrm{mol} \cdot \mathrm{m}^{-2} \cdot \mathrm{s}^{-1}\right)$, medium LED $\left(150 \mu \mathrm{mol} \cdot \mathrm{m}^{-2} \cdot \mathrm{s}^{-1}\right)$, and low LED $\left(400 \mu \mathrm{mol} \cdot \mathrm{m}^{-2} \cdot \mathrm{s}^{-1}\right)$ ] were compared with a nonilluminated treatment (control). Supplemental LED lights were set from 8:00 AM to 6:00 PM in the experimental period. Variations of daily light integral (DLI) during Expts. 1 and 2 were shown in Fig. 1.

Sampling leaf area and dry matter weight. To examine leaf area and total dry matter (DM) in different light treatments, three plants were randomly sampled from each treatment. The total leaf area (LA) was measured using a leaf area meter (Li-3100, Li-COR, Lincoln, NE). Subsequently, plants were destructively sampled and separated into leaves, peduncles, fruits, crowns, and roots, and then dried at $100{ }^{\circ} \mathrm{C}$ for $72 \mathrm{~h}$ with a circulation drier. The tissues were weighed after cooling to room temperature.

Estimating flower development and modeling. To estimate flower development, 
Table 1. Model parameters fitted for two strawberry cultivars of the first experiment from the transplanting date to the start of flowering.

\begin{tabular}{lccc}
\hline Treatment & Parameter & Mouikko & Tochiotome \\
\hline Full light & $\mathrm{a}$ & 1.05 & 1.05 \\
& $\mathrm{~b}$ & 2,000 & 3,000 \\
& $\mathrm{c}$ & 0.0105 & 0.0105 \\
\multirow{3}{*}{ Shading } & $R^{2}$ & 0.8246 & 0.8135 \\
& $\mathrm{a}$ & 1.04 & 1.0054 \\
& $\mathrm{~b}$ & 40,000 & 12,000 \\
& $\mathrm{c}$ & 0.0105 & 0.0105 \\
& $R^{2}$ & 0.6542 & 0.6209 \\
\hline
\end{tabular}

Table 2. Model parameters fitted for two strawberry cultivars of the second experiment from the transplanting date to the start of flowering.

\begin{tabular}{lcrr}
\hline Treatment & Parameter & Suzuakane & Tochiotome \\
\hline Full light & $\mathrm{a}$ & 0.4150 & 0.9774 \\
& $\mathrm{~b}$ & $1,941.3693$ & $350,000.0000$ \\
& $\mathrm{c}$ & 0.0437 & 0.0341 \\
\multirow{3}{*}{ Low LED } & $R^{2}$ & 0.7371 & 0.7854 \\
& $\mathrm{a}$ & 1.0090 & 1.0113 \\
& $\mathrm{~b}$ & $4,960.0735$ & $20,000.0000$ \\
Middle LED & $\mathrm{c}$ & 0.0111 & 0.0247 \\
& $R^{2}$ & 0.8069 & 0.8231 \\
& $\mathrm{a}$ & 1.0305 & 1.0184 \\
& $\mathrm{~b}$ & $3,363.6400$ & $1,334.9752$ \\
High LED & $\mathrm{c}$ & 0.0072 & 0.0192 \\
& $R^{2}$ & 0.9062 & 0.8907 \\
& $\mathrm{a}$ & 1.0054 & 1.0138 \\
& $\mathrm{~b}$ & $3,152.4999$ & 976.5910 \\
& $\mathrm{c}$ & 0.0134 & 0.0197 \\
& $R^{2}$ & 0.9291 & 0.9123 \\
\hline
\end{tabular}

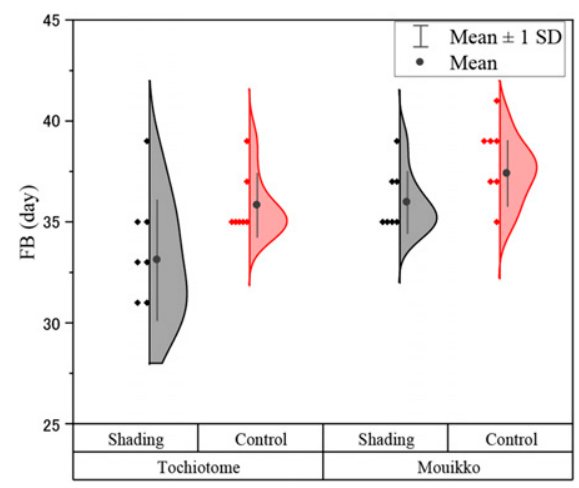

Fig. 4. Variations of full bloom (FB) for Mouikko and Tochiotome under shade compared with control treatments.

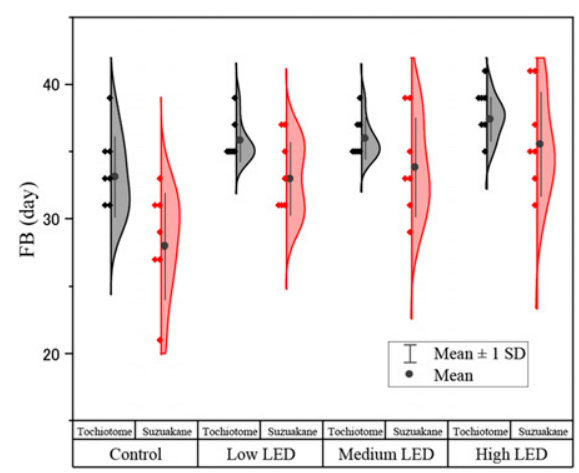

Fig. 5. Variations of full bloom (FB) for Tochiotome and Suzuakane under four lighting exposure treatments: high, medium, low, and control treatment. LED $=$ light-emitting diode. the second inflorescence was monitored daily to determine the ratio of flower proportion until full bloom in two experiments. Ten plants were randomly selected until termination of floral bud differentiation from each treatment every day to measure leaf number, count the number of floral buds, and observe floral development in Expt. 1. Seven plants were monitored in Expt. 2. Data were used for estimating flower development and modeling.

The parameters measured to evaluate flowering uniformity were time from flower beginning to full bloom (FB) within an inflorescence, time from transplanting to flowering (TB), and at the end of the experiment, the bud number $(\mathrm{BN})$ and the number of leaves between inflorescences in each plant were also recorded. The flower proportion collected in both experiments was fitted to the Gompertz curve as follows:

$$
\mathrm{Y}=\mathrm{a}^{*} \exp ^{-b^{*} \exp \left(-c^{*} t\right)}
$$

where $\mathrm{Y}$ is the flowering proportion, which represents the number of flowered plants vs. the total flower number; $a$ is the maximum proportion in each treatment; $b$ is the parameter related to the rate of the development process; $c$ is the parameter related to thermal time $\left({ }^{\circ} \mathrm{C} \cdot \mathrm{d}^{-1}\right)$ accumulated until the full bloom of the flower; and $t$ is accumulated thermal time.

Goodness-of-fit criteria for the model were evaluated by means of the square root of mean square error and the coefficient of determination. Data were analyzed with Origin 2019, and pairwise comparisons between treatments were performed using Tukey's honestly significant difference test.

\section{Results}

Description of flower development under different light exposure treatments. Gompertz models were adequate for describing the flower development stage as a function of accumulated thermal time from the date of transplant (Figs. 2 and 3); and in both experiments, the $R^{2}$ values ranged from 0.62 to 0.92 . For both cultivars, the data had a better fit under the high light illumination treatment than in the other treatments (Tables 1 and 2). In the first experiment, which explored the effect of shading, flowering speed was delayed when plants were shaded; whereas in the second experiment, which evaluated different lighting exposure, flowering speed was enhanced by adding LED lighting. Although each cultivar had different variances, the tendencies observed - that is, variation in lighting exposure during floral initiation altered the overall flowering time-were consistent in all treatments. However, the effects of lighting exposure on flower development in Mouikko were greater than those in Tochiotome in Expt. 1, indicating a genetic difference partially attributed to the reaction to light exposure between cultivars.

Uniformity of flowering under different lighting exposure treatments. The distributions of FB from the first experiment illustrate how shading prolongs the time to flowering as well as decreases its uniformity (Fig. 4). Data were fitted by using the Weibull model to express flowering duration with time, and reference lines were drawn by using the experimental data. The vertical axis represents the count of experimental strawberry, and the horizontal axis represents the time from flower initiation to full bloom (FB). Trend lines were added to express the variation of FB. The FB distribution was significantly narrowed by the light treatment. In Mouikko, the range of FB values was 36-39 d under full light exposure compared with $30-42 \mathrm{~d}$ in shading treatment. The same trend was found in Tochiotome, which had a range of $\mathrm{FB}$ values of 38-44 d, compared with 25-45 d.

When LED lighting was added in the second experiment, the range of variation of FB was significantly narrowed (Fig. 5). In high LED treatment, the FB of Suzuakane was in the range of $35-37 \mathrm{~d}$, and $90 \%$ of flower in blooming exposed over $35 \mathrm{~d}$. But the FB in the control treatment was in the range of $20-38 \mathrm{~d}$. The effect of light treatment in Tochiotome was not as obvious as that in Suzuakane. The range of control treatment was in the range of 30-40 d, and it was in the range of 35-38, 35-39, and 35$39 \mathrm{~d}$ for high, medium, and low treatment, respectively.

Analysis of BN among light treatments showed a positive correlation between the $\mathrm{BN}$ and light intensity both in Expts. 1 and 2 as shown in Figs. 6 and 7. What's more, the range of $\mathrm{BN}$ became narrow with the increase 


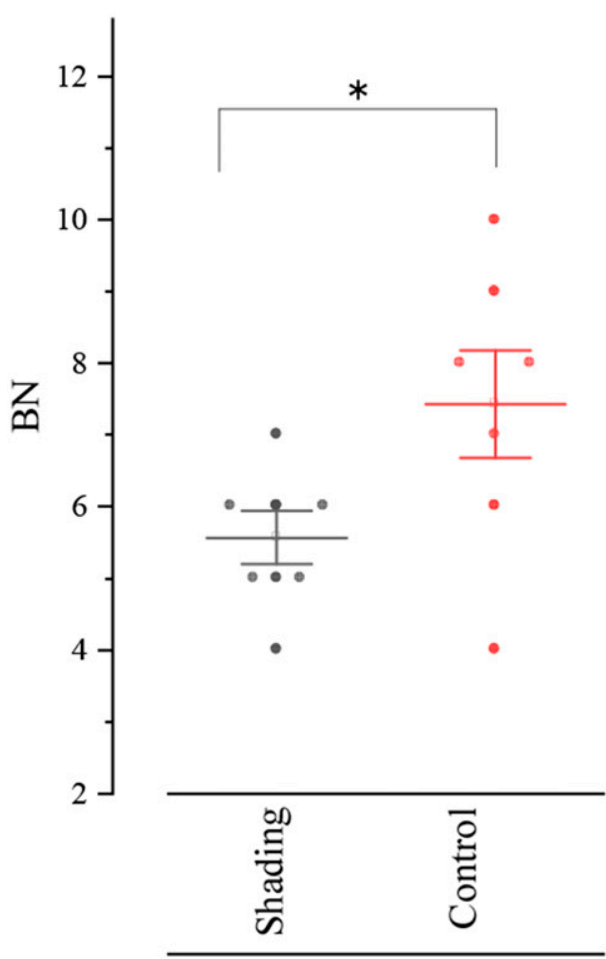

Totsuotome
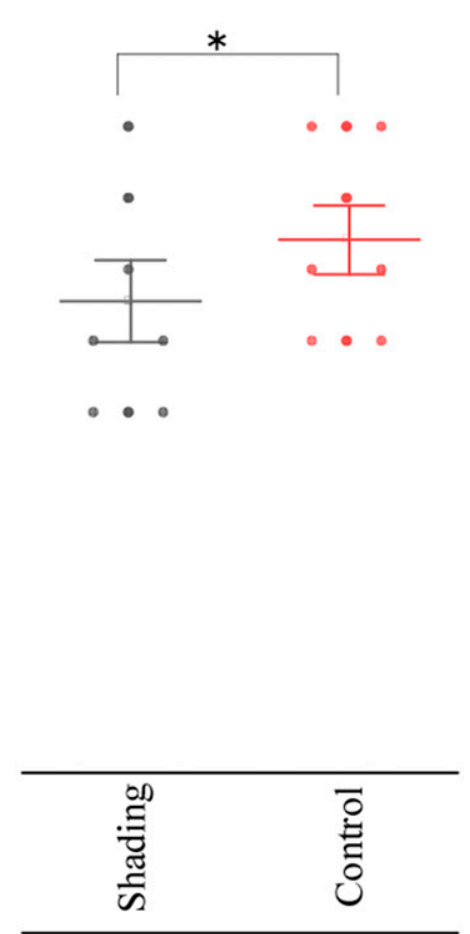

Mouikko
Fig. 6. Variations of bud number (BN) of two strawberry cultivars under shade and full light exposure treatments.

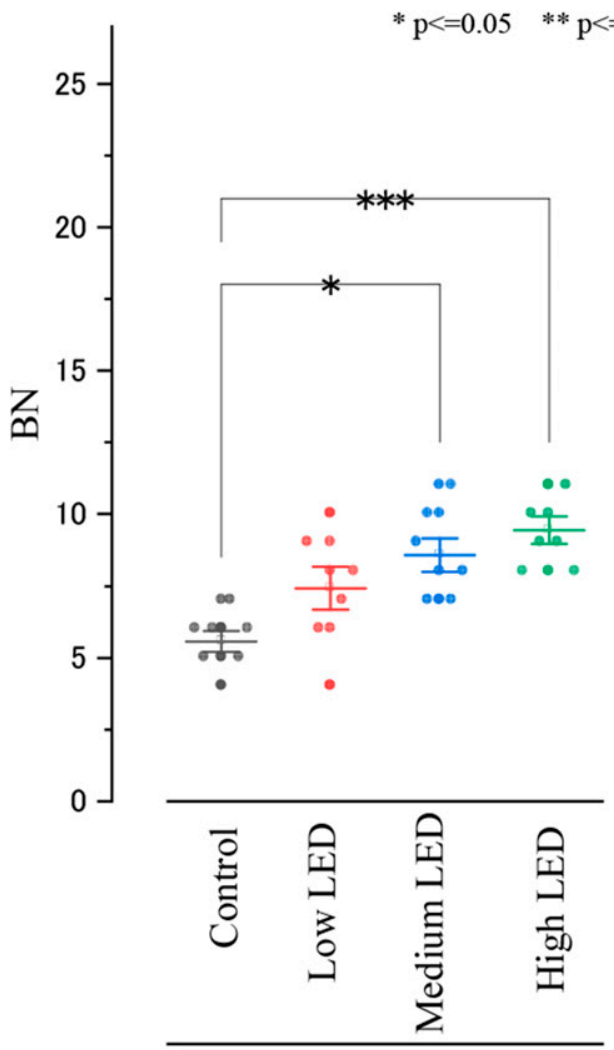

Totsuotome
$* * * \mathrm{p}<=0.001$

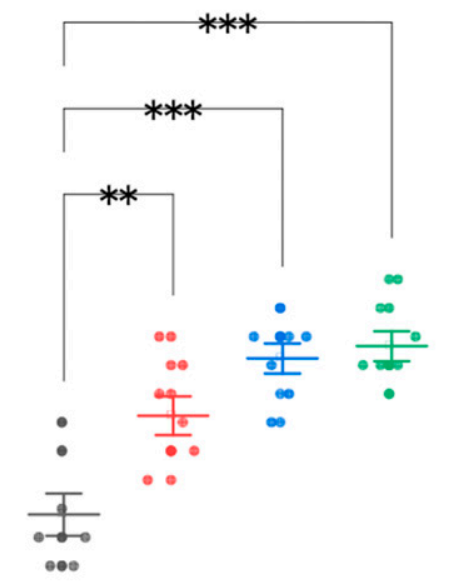

Mouikko

Fig. 7. Variations of bud number (BN) of two strawberry cultivars under four different light-emitting diode (LED) lighting treatments.

of light intensity. In Expt. 1, variations of range of $\mathrm{BN}$ in Mouikko was more obvious than that in Tochiotome. In shading treat- ment, the BN of Mouikko varied from $8.5 \pm$ 0.6 and $9.4 \pm 0.5( \pm \mathrm{SD})$ in full light treatment. The BN of Tochiotome varied from $5.5 \pm 0.4$ and $7.4 \pm 0.5( \pm$ SD of average $)$ in full light treatment. In Expt. 2, BN of Tochiotome was in the range of $5.5 \pm 0.6,7.4 \pm 0.5,8.5 \pm 0.5$, and $9.4 \pm 0.3$ for no LED, medium, low, and high light exposure, respectively. $\mathrm{BN}$ of Suzuakane was in the range of $6.8 \pm 0.7$, $10.2 \pm 0.6,12.2 \pm 0.5$, and $12.7 \pm 0.3$.

Effects of lighting treatments on photosynthetic ability. The effects of lighting treatments on photosynthetic production were evaluated on the basis of analyses of DM (dry matter), LA (leaf area), and NL (number of leaves). In Expt. 1, shading treatments delayed the growth and flowering of strawberry (Table 3); and variations of DM, LA, and NL were different in each treatment. DM decreased by about $40 \%$ when grown under $50 \%$ shade conditions in both cultivars. Because the time to flowering was delayed in the shading treatment, several more leaves were produced between the first and second inflorescences. In addition, the standard deviations of $\mathrm{DM}, \mathrm{LA}$, and $\mathrm{NL}$ in control treatments were smaller than those in the shading treatments, indicating that plant uniformity was negatively affected by shading. The similar trend was also found in Expt. 2; the standard deviations of DM, LA, and NL under the different LED lighting treatments were also relatively smaller compared with the control, further supporting the idea that increased light exposure promotes uniformity (Table 4).

\section{Discussion}

Effect of light intensity on uniformity of flowering. Different nonlinear models (e.g., logistic, Gompertz, and Richards models) have been used extensively to describe phenological development, fruit growth, and flower formation (Davidenco et al., 2017). In this study, the Gompertz model was used to describe flower development under different lighting treatments. Flower development was enhanced by increasing the light intensity and was delayed by shading. In both experiments, the coefficient of determination ( $R^{2}$ values) fitted the data better in the high light intensity treatment than in the other treatments, in both cultivars. Flowering time under favorable light conditions appeared to be close to the control distribution, which showed a relative moderate range in flowering.

Studies have shown that the number of floral buds increases in individual plants (and the days to flowering decrease) when supplemental, artificial light is applied, which indicates that light intensity affects floral induction and can feasibly enhance the yield (Choi et al., 2016). In the present study, this effect was evaluated from a population and uniformity perspective, and flowering time and floral bud production were found to be concentrated in a narrower range across the population, which indicates that uniform flower development also improves under favorable light conditions. Similar results have been observed in ornamental flowers such as chrysanthemums and Miltoniopsis orchids (Lopez and Runkle, 2006; Shahan et al., 2018). Therefore, high light 
Table 3. Comparison of dry matter (DM), leaf area (LA), and number of leaves between inflorescences (NL) in two cultivars, Mouikko and Tochiotome, from the beginning of the first experiment (BT), before flowering $(\mathrm{BF})$.

\begin{tabular}{|c|c|c|c|c|c|c|}
\hline \multirow[b]{2}{*}{ Cultivar } & \multirow[b]{2}{*}{ Treatment } & \multicolumn{2}{|c|}{ DM (g per plant) } & \multicolumn{2}{|c|}{$\mathrm{LA}\left(\mathrm{cm}^{2}\right)$} & \multirow[b]{2}{*}{ NL } \\
\hline & & BT & $\mathrm{BF}$ & BT & $\mathrm{BF}$ & \\
\hline \multirow[t]{2}{*}{ Tochiotome } & Shading & $3.21 \pm 0.54^{z}$ & $10.40 \pm 1.44$ & $277.03 \pm 52.10$ & $796.28 \pm 99.89$ & $\overline{4.48 \pm 0.40}$ \\
\hline & Full light & $3.23 \pm 0.61$ & $17.13 \pm 0.45$ & $273.03 \pm 51.92$ & $808.37 \pm 41.75$ & $4.00 \pm 0.49$ \\
\hline \multirow[t]{2}{*}{ Mouikko } & Shading & $2.79 \pm 0.31$ & $9.90 \pm 3.97$ & $225.52 \pm 33.96$ & $799.37 \pm 185.44$ & $4.75 \pm 0.34$ \\
\hline & Full light & $2.89 \pm 0.32$ & $12.97 \pm 2.13$ & $224.42 \pm 30.48$ & $831.36 \pm 66.35$ & $3.20 \pm 0.40$ \\
\hline
\end{tabular}

${ }^{\mathrm{z}}$ Values are the means of five independent experiments $\pm \mathrm{SE}$.

Table 4. Comparison of dry matter (DM), leaf area (LA), and number of leaves between inflorescences (NL) in two cultivars, Suzuakane and Tochiotome, from the beginning of the second experiment (BT), before flowering (BF).

\begin{tabular}{|c|c|c|c|c|c|c|}
\hline \multirow[b]{2}{*}{ Cultivar } & \multirow[b]{2}{*}{ Treatment } & \multicolumn{2}{|c|}{ DM (g per plant) } & \multicolumn{2}{|c|}{$\mathrm{LA}\left(\mathrm{cm}^{2}\right)$} & \multirow[b]{2}{*}{ NL } \\
\hline & & BT & $\mathrm{BF}$ & BT & $\mathrm{BF}$ & \\
\hline \multirow[t]{4}{*}{ Tochiotome } & Full light & $3.35 \pm 0.51^{z}$ & $9.28 \pm 0.98$ & $442.22 \pm 64.05$ & $721.62 \pm 64.05$ & $5.24 \pm 0.21$ \\
\hline & Low LED & $3.84 \pm 0.59$ & $10.40 \pm 0.78$ & $448.67 \pm 64.85$ & $770.62 \pm 54.85$ & $4.84 \pm 0.30$ \\
\hline & Middle LED & $3.59 \pm 0.88$ & $11.42 \pm 0.62$ & $459.31 \pm 68.05$ & $782.62 \pm 44.05$ & $4.61 \pm 0.38$ \\
\hline & High LED & $3.65 \pm 0.58$ & $11.66 \pm 0.43$ & $457.63 \pm 68.05$ & $790.20 \pm 38.05$ & $4.48 \pm 0.40$ \\
\hline \multirow[t]{4}{*}{ Suzuakane } & Full light & $3.33 \pm 0.54$ & $8.21 \pm 1.58$ & $448.67 \pm 62.05$ & $704.62 \pm 65.01$ & $5.3 \pm 0.30$ \\
\hline & Low LED & $4.18 \pm 0.52$ & $10.23 \pm 0.89$ & $450.05 \pm 64.12$ & $788.39 \pm 50.65$ & $4.97 \pm 0.34$ \\
\hline & Middle LED & $3.51 \pm 0.67$ & $12.02 \pm 0.76$ & $469.27 \pm 64.65$ & $797.28 \pm 45.35$ & $4.85 \pm 0.40$ \\
\hline & High LED & $3.71 \pm 0.49$ & $13.614 \pm 0.68$ & $463.00 \pm 62.05$ & $920.38 \pm 31.63$ & $4.75 \pm 0.54$ \\
\hline
\end{tabular}

${ }^{\mathrm{z}}$ Values are the means of three independent experiments \pm SE.

intensity not only results in earlier flowering and enhanced yield but also improves the uniformity of these traits across a population.

Relationship between uniformity of flowering and photosynthetic performance. In this study, the amount of total light energy that plants received varied according to light treatment. In the first experiment, the shading ratio was about $50 \%$; in the second experiment, LED supplemental lights were used and increased the total light exposure. Because of the difference in photosynthetic dynamics, DM production and LA were significantly different at the flowering stage. For instance, after the shading treatment, the standard deviations in DM were $\pm 1.44 \mathrm{~g}$ for Tochiotome and $\pm 3.97 \mathrm{~g}$ for Mouikko, compared with those of the controls of $\pm 0.45 \mathrm{~g}$ and $\pm 2.13 \mathrm{~g}$, respectively. This higher deviation from the mean data indicates that shading causes more variability in these traits, and these same trends were also found in LA and NL. However, when supplemental light was applied, the standard deviations of DM, LA, and NL showed relatively small deviations from the mean data. These results suggest that both flowering uniformity and photosynthesis are affected by light energy input. Yoshida et al. (2012) found that the amount of photosynthesis is correlated with flower initiation, verifying that photosynthetic capability has a significant influence on flowering time. How much light is intercepted as having a significant impact on so many traits makes sense, because leaves are the major pathway of energy into plants where carbon gain is realized. Our results also confirmed the increased export of carbohydrates is critical for floral transition (Corbesier et al., 1998). When conditions are favorable, and carbon supply and nutrients are not limited, wild strawberry produces leaves of constant size; whereas if any of these conditions are less favorable in an environment, leaf size changes in response to environmental conditions (Thomas et al., 1982; Thomas and Brian, 1986). In our study, we found similar results under greenhouse conditions with three commercial strawberry cultivars.

Uniformity of flower development can be used as an effective short-term index to quantify environmental effects on the field production of strawberry in environmental management. If strawberries were cultivated in a relative optimum environment, the flower development will show high uniformity and stability, which is convenient for the management of production.

\section{Conclusion}

In greenhouse strawberry production, it is difficult to control the rate of growth and realize stable yields - as in field productionbecause of the lack of uniformity in flower initiation. Our analysis on the uniformity of flower development provides new insights into the production processes. This work demonstrates that accumulation of DM is necessary for proper inflorescence formation, and that increasing its accumulation by improving the environmental conditions will increase the uniformity of flower development.

Therefore, providing a favorable environment that promotes photosynthesis is a valuable method to ensure uniformity of flower development and to encourage steady growth. In addition, our research suggests that supplemental lighting used in strawberry greenhouse production contributes not only to an increase in yield but also to the stability of flower initiation. This method can be used to effectively control and improve the uniformity of flower development, especially in forcing culture of strawberry production at highlatitude areas.

\section{Literature Cited}

Awang, Y.B. and J.G. Atherton. 1995. Growth and fruiting responses of strawberry plants grown on rockwool to shading and salinity. Scientia Hort. 62:25-31.

Cervantes, L., M.T. Ariza, J.A. Gomez-Mora, L. Miranda, J.J. Medina, C. Soria, and E. MartinezFerria. 2019. Light exposure affects fruit quality in different strawberry cultivars under field conditions. Scientia Hort. 252:291-297.

Choi, H.G., Y.M. Byoung, and N.J. Kang. 2016. Correlation between strawberry (Fragaria ananassa Duch.) productivity and photosynthesisrelated parameters under various growth conditions. Fron. Plant Sci. 1607:1-13.

Choi, H.G., B.Y. Moon, N.J. Kang, J.K. Kwon, K. Bekhzod, K.S. Park, and S.Y. Lee. 2014. Yield loss and quality degradation of strawberry fruits cultivated under the deficient insolation conditions by shading. Hort. Envi. Biol. 55:263-270.

Corbesier, L., P. Lejeune, and G. Bernier. 1998. The role of carbohydrates in the induction of flowering in Arabidopsis thaliana: Comparison between the wild type and a starchless mutant. Planta 06:131-137.

Davidenco, V., J.A. Arguello, P. Monica, and C.R.C. Vega. 2017. Day length modulates precocity and productivity through its effect on developmental rate in Origanum vulgare ssp. Scientia Hort. 218:164-170.

Kumakura, H. and Y. Siilsiildo. 1995. Effects of temperature and light conditions on flower initiation and fruit development in strawberry. Jpn. Agr. Res. Q. 29:241-250.

Lopez, R.G. and E.S. Runkle. 2006. Temperature and photoperiod regulate flowering of potted Miltoniopsis orchids. HortScience 41:593-597.

Miyashita, C., K. Yuka, and O. Isao. 2019. Utility of parthenocarpic interspecific hybrids between Vaccinium corymbosum and Vaccinium virgatum for breeding blueberry cultivars suitable for cluster harvesting. J. Jpn. Soc. Hort. Sci. 88(2):180-188

Mochizuki, Y., S. Sekiguchi, N. Horiuchi, T. Aung, and I. Ogiwara. 2019. Photosynthetic characteristics of individual strawberry (Fragaria $\times$ ananassa Duch.) leaves under short-distance lighting with blue, green, and red LED Lights. J. Amer. Soc. Hort. Sci. 54:452-458

Nestby, R. and A. Sønsteby. 2017. Effect of plant type and delayed planting on growth and yield parameter of two short day strawberry cultivars in open field. J. Berry Res. 7:179-194.

Opstad, N., A. Sønsteby, U. Myrherim, and O.M. Heide. 2011. Seasonal timing of floral initiation in strawberry: Effects of cultivar and geographic location. Scientia Hort. 129:127-134.

Shahan, R., C. Zawora, H. Wight, J. Sittmann, W.P. Wang, S.M. Mount, and Z.C. Liu. 2018. Consensus co-expression network provide insights into wild strawberry flower and fruit development. Plant Physiol. 178:202216.

Sønsteby, A., N. Opstad, and O.M. Heide. 2013. Environmental manipulation for establishing high yield potential of strawberry forcing plants. Scientia Hort. 157:65-73.

Takeda, F., D.M. Glenn, A. Callahan, J. Slovin, and G.W. Stutte. 2010. Delaying flowering in shortday strawberry transplants with photo selective nets. Inter. Fruit. Sci. 10:134-142. 
Thomas, W.J., J.F. Chabot, and F.C. Brain. 1982. Effects of light and nutrients on leaf size, $\mathrm{CO}_{2}$ exchange, and anatomy in wild strawberry (Fragaria virginiana). Plant Physiol. 70:1044-1048.

Thomas, W.J. and F.C. Brian. 1986. Leaf dynamics and profitability in wild strawberries. Oecologia 69:296-304.

Tsuruyama, J. and T. Shibuya. 2018. Growth and flowering responses of seed-propagated strawberry seedlings to different photoperiods in controlled environment chambers. HortTechnology 28:453-458.

Yoshida, Y., E. Ozaki, K. Murakami, and T. Goto. 2012. Flower induction in June-bearing strawberry by intermittent low temperature storage. J. Jpn. Soc. Hort. Sci. 81(4):343-349.

Yoshida, Y., Y. Morimoto, and K. Yokoyama 1997. Soil organic substances positively affect carbon dioxide environment in green- house and yield in strawberry. J. Jpn. Soc. Hort. Sci. 65:791-799.

Young, W.N. and J.J. Ho. 2013. Breeding of 'Daewang' strawberry for forcing culture with good taste and fragrance. Kor. J. Hort. Sci. Technol. 31(5):648-651.

Zahedi, S.M. and H. Sarikhani. 2017. The effect of end of day far-red light on regulating flowering of short-day strawberry in a long-day situation. J. Rus. Plant Physiol. 64(1):83-90. 